University of Wollongong

Research Online

Faculty of Engineering - Papers (Archive)

Faculty of Engineering and Information

Sciences

2003

\title{
Neutron dosimetry with planar silicon p-i-n diodes
}

Anatoly B. Rosenfeld

University of Wollongong, anatoly@uow.edu.au

M. Yudelev

Wayne State University, Detroit

M. L. Lerch

University of Wollongong, mlerch@uow.edu.au

I. Cornelius

University of Wollongong, iwan@uow.edu.au

P. Griffin

Sandia National Laboratory, Albuquerque, USA

See next page for additional authors

Follow this and additional works at: https://ro.uow.edu.au/engpapers

Part of the Engineering Commons

https://ro.uow.edu.au/engpapers/30

\section{Recommended Citation}

Rosenfeld, Anatoly B.; Yudelev, M.; Lerch, M. L.; Cornelius, I.; Griffin, P.; Perevertailo, V. L.; Anokhin, I. E.; Zinets, O. S.; Khivrich, V. I.; Pinkovskaya, M.; Alexiev, D.; and Reinhard, M.: Neutron dosimetry with planar silicon p-i-n diodes 2003.

https://ro.uow.edu.au/engpapers/30

Research Online is the open access institutional repository for the University of Wollongong. For further information contact the UOW Library: research-pubs@uow.edu.au 


\section{Authors}

Anatoly B. Rosenfeld, M. Yudelev, M. L. Lerch, I. Cornelius, P. Griffin, V. L. Perevertailo, I. E. Anokhin, O. S. Zinets, V. I. Khivrich, M. Pinkovskaya, D. Alexiev, and M. Reinhard 


\title{
Neutron Dosimetry With Planar Silicon p-i-n Diodes
}

\author{
Anatoly B. Rosenfeld, Senior Member, IEEE, Mark Yudelev, Michael L. F. Lerch, Member, IEEE, \\ Iwan Cornelius, Senior Member, IEEE, Patrick Griffin, Member, IEEE, Vladimir L. Perevertailo, Member, IEEE, \\ Igor E. Anokhin, Oleg S. Zinets, Vladimir I. Khivrich, Miroslava Pinkovskaya, Dimitry Alexiev, and \\ Mark Reinhard, Member, IEEE
}

\begin{abstract}
New nonionizing energy losses (NIEL) sensors based on silicon planar p-i-n diodes of different geometry have been investigated and their response to fast neutron field compared with bulk diodes. The possibility of obtaining a wide range of sensitivities in these NIEL sensors simultaneously with measurements of IEL has been demonstrated.
\end{abstract}

Index Terms-Gamma dosimetry, neutron dosimetry, p-i-n diode.

\section{INTRODUCTION}

$\mathbf{P}$ RACTICAL and simple measurements of nonionizing energy losses (NIEL) and ionizing energy losses (IEL) in neutron and proton fields is an important issue for quality assurance in the radiation environment in space and at different radiation facilities. The best monitor for NIEL in any radiation field should be based on the same material ( $\mathrm{Si}$ or GaAs) as the electronic devices subject to radiation damage. NIEL are proportional to the bulk radiation damage in semiconductor devices resulting from displacement of atoms from their sites. The change in electrical characteristics acts as a suitable monitor of NIEL in devices affected by such atomic displacement. One can measure the effects of NIEL by monitoring the change in lifetime, diffusion length, or concentration of charge carriers.

The suitable sensor for NIEL measurements in terms of $1-\mathrm{MeV}(\mathrm{Si})$ fluence is a $\mathrm{p}-\mathrm{i}-\mathrm{n} \mathrm{Si}$ diode. The forward voltage of the $\mathrm{p}$-i-n diode increases due to radiation degradation of the carrier lifetime and the changing resistivity of the material [1]-[3]. The sensitivity of the p-i-n diode depends on the initial Si-material [4], [5] and its geometry [2]. A sensor with a wide dynamic range of sensitivities is required in applications where the neutron dose range is not known. Such a sensitivity range is almost impossible to achieve in a single bulk p-i-n diode; beside that, the manufacturing of long base bulk diodes is both a time-consuming and expensive process. The aim of this paper

Manuscript received July 22, 2003; revised September 10, 2003. This work was supported by the Australian Institute for Nuclear Science and Engineering (AINSE) by Research Grant 972 .

A. B. Rosenfeld, M. L. F. Lerch, and I. Cornelius are with the Centre for Medical Radiation Physics, University of Wollongong, Wollongong, NSW, 2522, Australia (e-mail: anatoly@uow.edu.au).

M. Yudelev is with Karmanos Cancer Institute, Wayne State University, Detroit, MI 48201 USA.

P. Griffin is with the Sandia National Laboratory, Albuquerque, NM 87185 USA.

V. L. Pervertailo is with the SPA-BIT "Detector," $254163 \mathrm{Kiev}$, Ukraine.

I. E. Anokhin, O. S. Zinets, V. I. Khivrich, and M. Pinkovskaya are with the Institute for Nuclear Research, 252028 Kiev, Ukraine.

D. Alexiev and M. Reinhard are with the Australian Nuclear Science and Technology Organization (ANSTO), Menai NSW 2234, Australia.

Digital Object Identifier 10.1109/TNS.2003.821390

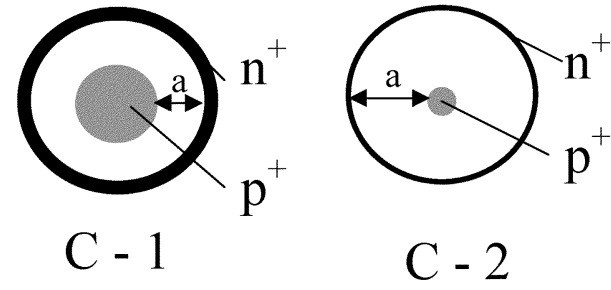

Fig. 1. Circular planar diodes $\mathrm{C}-1$ and $\mathrm{C}-2$. For $\mathrm{C} 1$, the diameter of the $\mathrm{P}+$ region is $1.5 \mathrm{~mm}$, thickness of $\mathrm{n}+$ ring is $0.5 \mathrm{~mm}$, and the radial base length (labeled "a") is $0.5 \mathrm{~mm}$. For diode $\mathrm{C} 2, \mathrm{a}=1.4 \mathrm{~mm}$, the diameter of the $\mathrm{P}+$ region is $0.5 \mathrm{~mm}$ and thickness of $\mathrm{n}+$ ring is $0.1 \mathrm{~mm}$.

is first to study the neutron response of planar p-i-n diodes with different geometry and compare them with a bulk diode. Second, this paper studies the possibility of simultaneous IEL measurements with the same sensor in a mixed radiation field. The authors have developed prototype, multirange planar $\mathrm{p}-\mathrm{i}-\mathrm{n}$ diodes for NIEL dosimetry and investigated their application as on-line neutron and proton dose monitors with simultaneous IEL dosimetry.

\section{MATERIALS AND MethodS}

Four different types of ion-implanted p-i-n diodes have been developed and manufactured. The ion-implanted bulk p-i-n diodes with a base length of $\sim 1 \mathrm{~mm}$ and cross section of $\mathrm{p}+$ and $\mathrm{n}+1.2 \mathrm{~mm}^{2}$ were fabricated from high-purity n-type silicon (referred to herein as the D-type diode). They had similar geometry to the low-resistivity dosimeters studied in [6]. These diodes were irradiated in a neutron field at the Sandia National Laboratories (SNL) Pulse Reactor Facility (SPR-III), and in a fast neutron therapy (FNT) facility (Harper Hospital, Detroit).

Two types of planar p-i-n diodes were developed; circular planar p-i-n diodes (Type C, Fig. 1) and planar diodes with a linear array of p+ contacts (Type L and G, Fig. 2). The silicon wafer thickness was $350 \mu \mathrm{m}$. These diodes were irradiated in FNT facility in a water phantom and an A-150 plastic phantom as well as on a $3-\mathrm{MeV}$ proton beam in free air geometry. The radial base-length of the $i$ region in the C-type $\mathrm{p}-\mathrm{i}$-n diodes was 0.5 and $1.45 \mathrm{~mm}$ for $\mathrm{C}-1$ and $\mathrm{C}-2$, respectively.

\section{A. SPR-III Reactor Facility}

The irradiation was done in the fast burst reactor cavity at calibrated points with a well-known ratio of neutron/gamma dose. The equivalent (1-MeV)Si fluence, $\Phi(1-\mathrm{MeV}) \mathrm{Si}$ was determined using monitor foils and a neutron spectrum, which was unfolded using a set of activation foils [7]. The ratio of the $1-\mathrm{MeV}(\mathrm{Si})$ neutron fluence to the gamma dose was $3 \times$ 

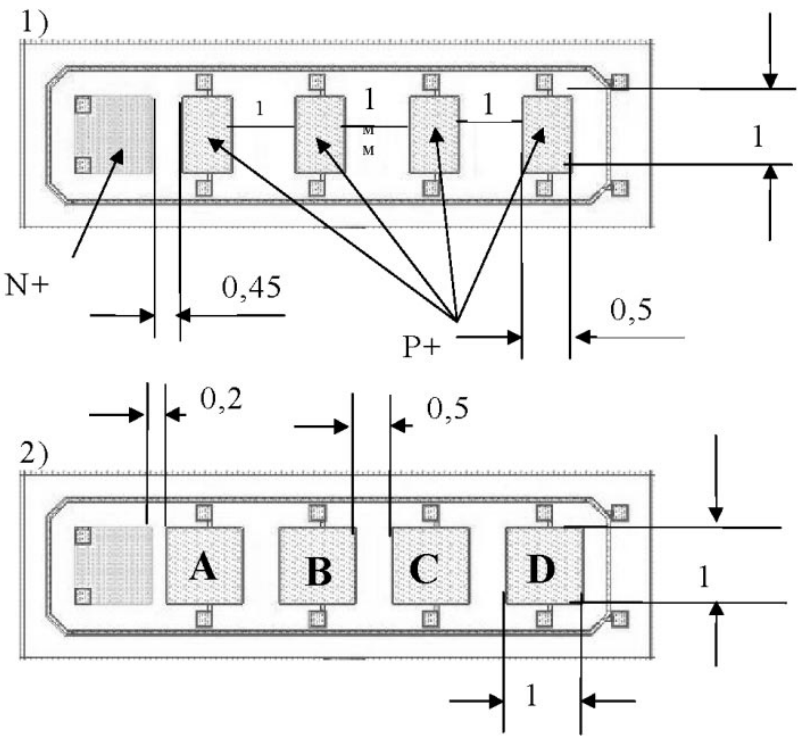

Fig. 2. Planar p-i-n diode array with type-L labeled (1) and type-G labeled (2).

$10^{11} 1 \mathrm{MeV} \mathrm{n} / \mathrm{cm}^{2}$ per 1-Gy(Si). A special reader with data acquisition system was developed at the Centre for Medical Radiation Physics (CMRP), University of Wollongong (UoW), for on-line measurements of the sensor during the irradiation. The diode was connected to the reader via $50 \mathrm{~m}$ of cable. The reader has an RS232 interface that connects to a printer or to a data collection computer and allows readout of the p-i-n diode with any sequences. For this experiment, the p-i-n diode was read out automatically every $20 \mathrm{~s}$. The tissue-equivalent (TE) neutron dose rate was $\sim 0.15 \mathrm{cGy}(\mathrm{TE}) / \mathrm{s}$.

\section{B. FNT Facility}

The neutron beam was produced using a superconducting cyclotron at the FNT facility, Detroit [8]. Neutrons are produced via $48.5-\mathrm{MeV}$ deuteron bombardment of a Be target. The average energy of neutrons was about $20 \mathrm{MeV}$, with maximum energy $48.5 \mathrm{MeV}$.

One of the p-i-n D-diodes was hermetically sealed inside a 1.2-mm-diameter catheter for direct, in water, application, and the other D, C, and L planar diodes were encapsulated in A-150 plastic with a 10-m-long cable. Irradiation of all diodes was in a water tank. An ionizing chamber monitored the total dose. A paired detector method using a TE ionization chamber (IC) and a miniature GM tube was used to separate the gamma and neutron tissue dose. An automatic data acquisition system, developed at the cyclotron facility, was used for the readout of $\Delta V_{f}$ of diodes and accelerator beam current simultaneously with the frequency of measurements of $10 \mathrm{~Hz}$. The signal from the diode was amplified by a factor of 10 .

\section{Proton Irradiation Facility}

Experiments on proton irradiation and IEL studies were performed with the Heavy Ion Microprobe (HIMP) at the Australian Nuclear Science and Technology Organization (ANSTO), Lucas Heights, Australia. [9]. For the present experiment, a 3-MeV proton beam, focused to a beam diameter of $10 \mu \mathrm{m}$, was used for IEL measurements. This beam is the most penetrating available at the facility, and it corresponds to a range in silicon of $100 \mu \mathrm{m}$. The ion beam-induced charge (IBIC) setup was used to derive a 2-D image of the median charge collected $\mathrm{Q}(\mathrm{x}, \mathrm{y})$ at each pixel [10].A beam fluence of approximately $10^{2}$ ions/s is established in IEL mode to ensure the sample is not damaged during analysis. The maximum scan size obtained with the microprobe is approximately $4 \times 4 \mathrm{~mm}^{2}$. An IBIC scan was carried out on device $\mathrm{C} 2$ with the central $\mathrm{p}^{+}$ region biased at voltages of 0 and $-400 \mathrm{~V}$ relative to $\mathrm{n}+$ region.

The experiment was conducted to investigate the response of the sensors to NIEL effects incurred by exposure to protons. The beam was collimated to an area of $\mathrm{A}=2 \times 2 \mathrm{~mm}^{2}$ and the L-type sample mounted on the sample holder. The proton fluence was controlled by Faradey cap. As the dimensions of the device are larger than the beam area, it was necessary to expose the device via three separate irradiations. After each irradiation, the forward voltage was measured (using a 1-mA current source) between $\mathrm{p}^{+}$fingers A, B, C, and D (as shown in Fig. 2) and the $\mathrm{n}^{+}$region.

\section{RESULTS}

Measurements using the D-, C-, L-, and G-type silicon pin diodes in neutron fields were carried out to understand the effect of the diode geometry on its response and compare this effect in planar and bulk diodes. On-line neutron dosimetry with pin diodes was also investigated. Based on these measurements, the best geometry of planar multirange pin diode for simultaneous NIEL and IEL were able to be determined.

\section{A. SPR-III Neutron Field}

Fig. 3 (solid line) shows the response of the D-type p-i-n diode with a base length of $1.0 \mathrm{~mm}$ in the SPR-III neutron field. The response of the $1.2 \times 1.8 \times 1.8-\mathrm{mm}^{3}$ diode under $25-\mathrm{mA}$ readout current and fabricated with similar technology based on low-resistivity silicon $(\sim 50-100 \Omega \mathrm{cm})$ [6] is also shown (Fig. 3, dashed line) for comparison.

The diode manufactured from low-resistivity silicon clearly displays saturation characteristics in its response curve for doses $>1500$ rad (tissue) and lower sensitivity under the same base length. The sensitivity of the higher resistivity $\mathrm{p}-\mathrm{i}-\mathrm{n}$ diodes to ${ }^{60}$ Co photons was $1.24 \times 10^{-3} \mathrm{mV} / \mathrm{cGy}(\mathrm{TE})$, and for fast fission neutrons, it was $2.74 \mathrm{mV} / \mathrm{cGy}(\mathrm{TE})$. The apparent saturation of the response, observed above $8000 \mathrm{cGy}$ (TE) in the solid curve of Fig. 3, was due to limitations of the reader and is not related to the diode.

\section{B. Online Measurements on an FNT Beam}

We have investigated the application of the neutron dosimetric diode in an on-line mode at the FNT facility. Experiments were carried out in a $15 \times 15-\mathrm{cm}^{2}$ open radiation field and a $30 \times 30-\mathrm{cm}^{2}$ blocked field (with an equivalent tungsten thickness of $93.5 \mathrm{~mm}$ in the latter case). All measurements were done at a depth of $5 \mathrm{~cm}$ in water with the diode being placed inside an A-150 jig of $15 \mathrm{~mm}$ diameter and $135 \mathrm{~mm}$ length. The accelerator current was 8-12 $\mu \mathrm{A}$. One monitoring unit $(\mathrm{MU}) \sim 1 \mathrm{cGy}$ at $\mathrm{D}_{\max }(\sim 0.9 \mathrm{~cm}$ in water). 


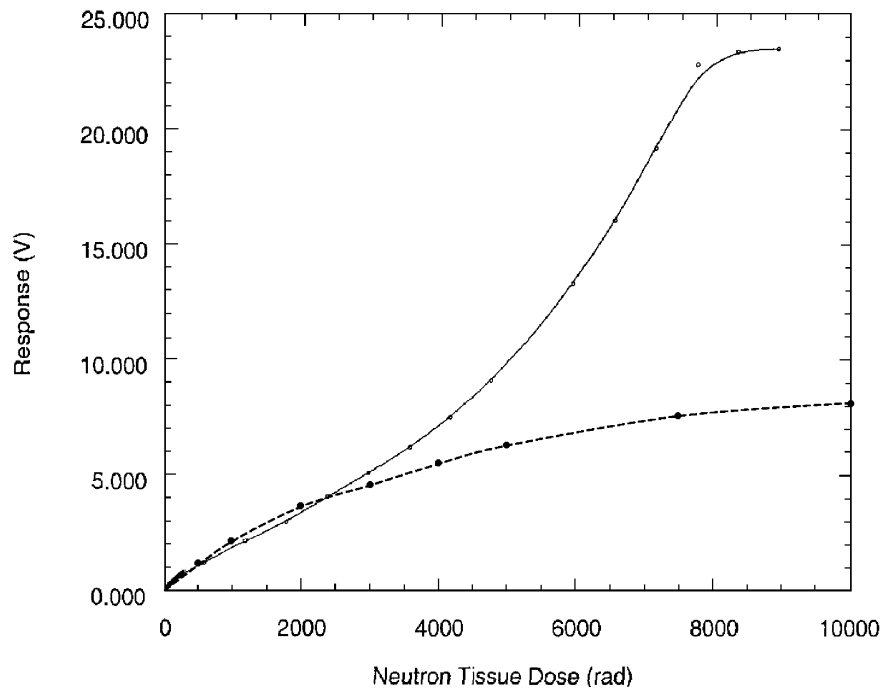

Fig. 3. Solid line shows the response of the p-i-n diode with a base length of $1.0 \mathrm{~mm}$ in the SPR-III neutron field. The dashed line is the response of the diode fabricated using similar technology based on low resistivity silicon $(\sim 50-100 \Omega \mathrm{cm})$.

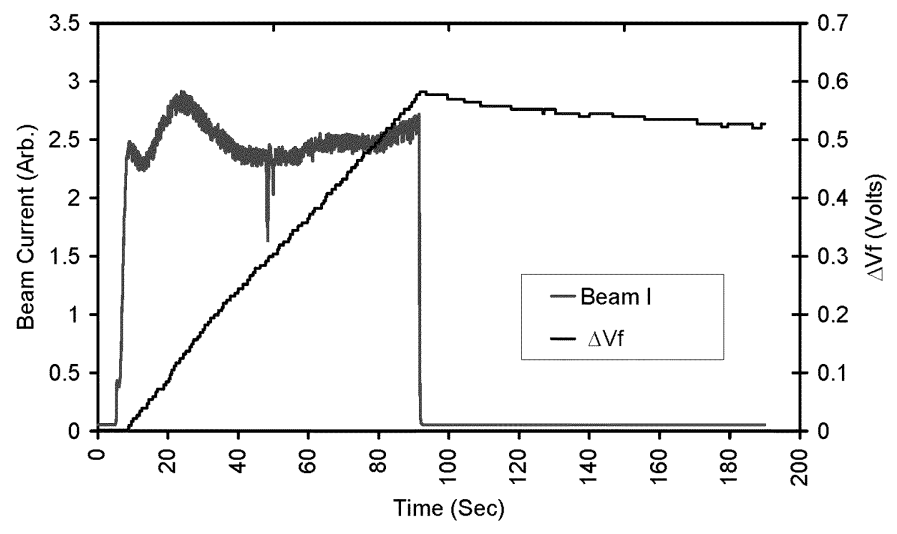

Fig. 4. Measurements taken using D-type diode in open field.

The blocking of the neutron beam with tungsten will moderate the initial neutron spectra and dramatically increase the gamma component of the field. The gamma dose at $5 \mathrm{~cm}$ was $8 \%$ and $30 \%$ of the total tissue equivalent (TE) dose in the $15 \times 15-\mathrm{cm}^{2}$ open field and $30 \times 30-\mathrm{cm}^{2}$ blocked field, respectively.

Fig. 4 demonstrates the results of measurements taken using the D-11 p-i-n diode in the open field. The total neutron dose delivered was 50 cGy during a 90-s exposure in the open field configuration. In the blocked field delivery mode, a 16.6-cGy neutron dose was delivered during a 140-s exposure.

The response of the diode clearly correlates with the accelerator current. The integral dose and the neutron dose rate of NIEL can also be monitored. Increasing the gamma dose component in the blocked field configuration has no effect on the measurement of the neutron dose.

Fig. 4 also shows the fading associated with room temperature annealing of unstable radiation defects after the irradiation has stopped. It is interesting to note that under open field conditions, the observed fading was $\sim 1.6 \%$ within the first $1.5 \mathrm{~min}$, whereas for the $30 \times 30$ blocked field experiments, fast fading

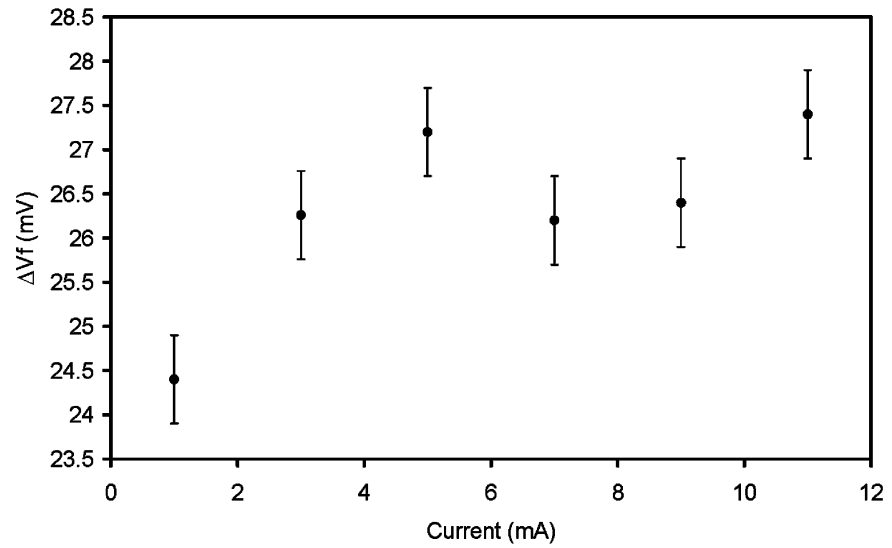

Fig. 5. Response of the diode versus accelerator current for dose increment of $25 \mathrm{MU} \sim 21 \mathrm{~Gy}$ at the point of irradiation.

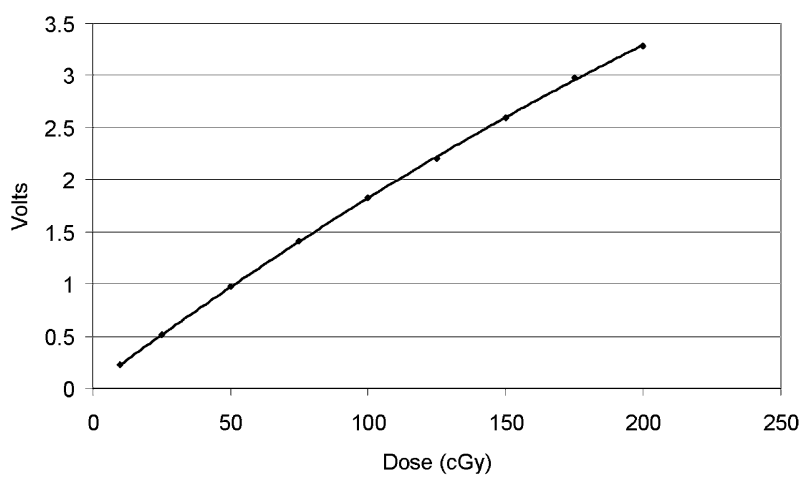

Fig. 6. On-line response of D-type p-i-n diode for neutron dose up to $200 \mathrm{cGy}$. The beam current was $11 \mu \mathrm{A}$, and the open field size was $15 \mathrm{~cm} \times 15 \mathrm{~cm}$.

was not observed within the first minute after the beam was turned off. It implies that for lower dose rates $(0.1 \mathrm{cGy} / \mathrm{s}$ in the case of blocked field in comparison with $0.5 \mathrm{cGy} / \mathrm{s}$ for open field), a dynamic equilibrium can be achieved between the stable and unstable defects. Equilibrium is achieved via room temperature annealing during the irradiation, which influences the response of the diode in the on-line mode. For more accurate dosimetry of low-dose-rate neutron fields in on-line mode, the diode should be calibrated on-line, in the same neutron field.

To understand this response effect, we investigated the diode response (D-type) versus neutron dose rate for accelerator beam currents of $1-11 \mu \mathrm{A}$. Irradiation was in an open $10 \times 10-\mathrm{cm}^{2}$ field at a depth of $5 \mathrm{~cm}$. Fig. 5 shows the response of the diode $\left(\Delta V_{f}\right.$ increments) in on-line mode versus accelerator current for a dose increment of $25 \mathrm{MU} \sim 21 \mathrm{cGy}$ at the point of irradiation. It is clear that for I $>3 \mu \mathrm{A}$, the response of the diode was $26.7 \pm 0.6 \mathrm{mV}$, i.e., within $2.2 \%$, whereas for $1-\mu \mathrm{A}$ current, a clear reduction in the response to $24.5 \mathrm{mV}$, which is presumably associated with on-line fading during the irradiation. For low-dose-rate applications, this should be taken into account if calibration has been done under higher dose rate conditions, i.e., for dose rate $\geq 0.1 \mathrm{cGy} / \mathrm{s}$.

A test of the dose response in on-line mode demonstrated good linearity of D-diode for doses up to $1000 \mathrm{cGy}$. Fig. 6 shows the response of diodes used in on-line mode is within doses of interest for medical and radiobiological space applications. To understand the nature of the response of these diodes, we 


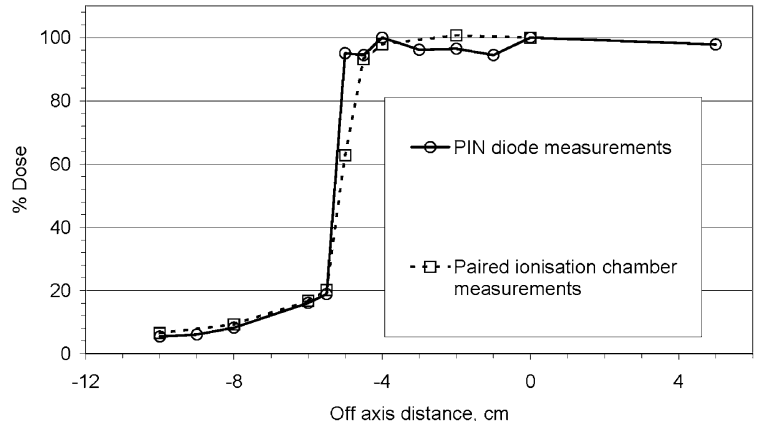

Fig. 7. Measured neutron beam profile using our D-type p-i-n diode.

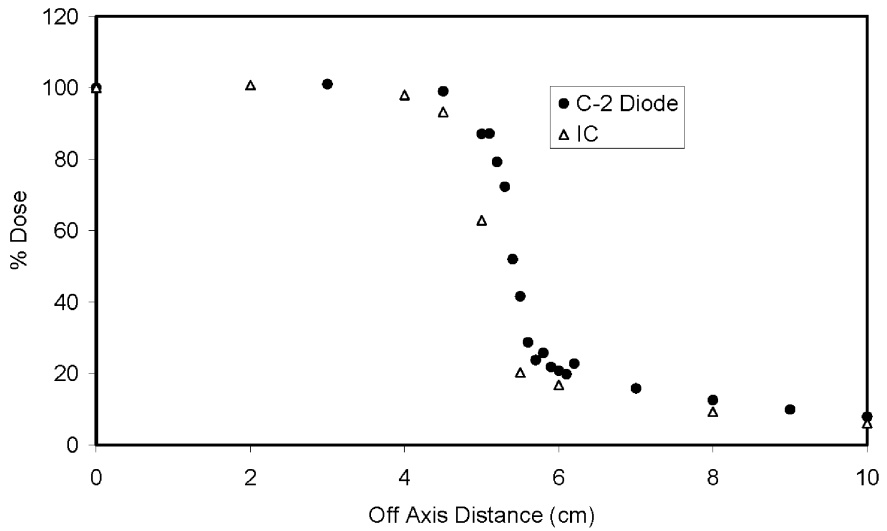

Fig. 8. Measured neutron beam profile using our $\mathrm{C}-2$ p-i-n diode. The measurement was made at a depth of $5 \mathrm{~cm}$ in a water phantom in a $10 \times 10-\mathrm{cm}^{2} \mathrm{~d}+$ Be neutron field.

investigated the response of the silicon p-i-n diode in buildup region where charge particle equilibrium does not exist.

We investigated the response of the $\mathrm{C} 2 \mathrm{p}-\mathrm{i}$-n diode in a water phantom build-up region, with $\mathrm{D}_{\max }$ at $\sim 9.5 \mathrm{~mm}$ for a $10 \times$ 10 -cm open field and compared it with the neutron dose derived from paired method measurements. The diode response under the same radiation conditions in an A-150 phantom did not derive the correct dose in the build-up region. This result clearly demonstrates that it is impossible to apply the p-i-n diode neutron dosimeter for TE neutron dosimetry in a charge particle disequilibrium region. The characteristics of buildup in such a region totally depend on the phantom material and neutron spectrum. The p-i-n diode is always measuring displacement KERMA, which is proportional to neutron fluence in a medium, whereas the absorbed dose is a measure of the ionization produced by secondary charged particles. For depths $>0.9 \mathrm{~cm}$, the relative diode response and neutron dose obtained from measurements was in good agreement with those obtained using an IC.

Figs. 7 and 8 shows the resulting beam profile using D-type and C-2 p-i-n diodes, respectively. Measurements were made at a depth of $5 \mathrm{~cm}$ in a water phantom with a $10 \times 10-\mathrm{cm}^{2}$ neutron field produced from the $48.5-\mathrm{MeV} \mathrm{d}+\mathrm{Be}$ reactions. The diode has a spatial resolution of $\sim 1 \mathrm{~mm}$, which makes the measurements of the neutron dose profile in mixed gamma neutron field much simpler than methods using a paired detector (TE ionizing chamber and Geiger-Muller tube). Fig. 8 shows similar beam profile measured at the same depth in water using C-2

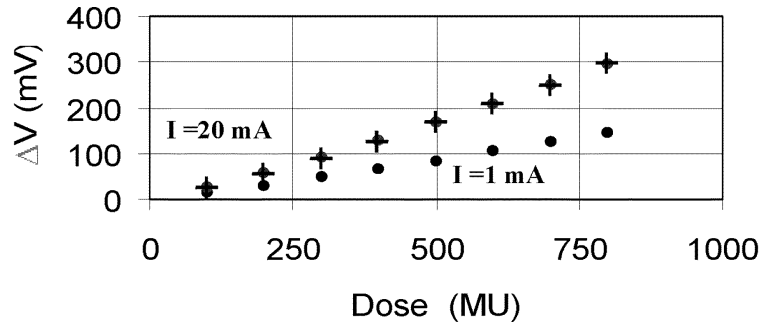

Fig. 9. Neutron response of the C-1 diode.

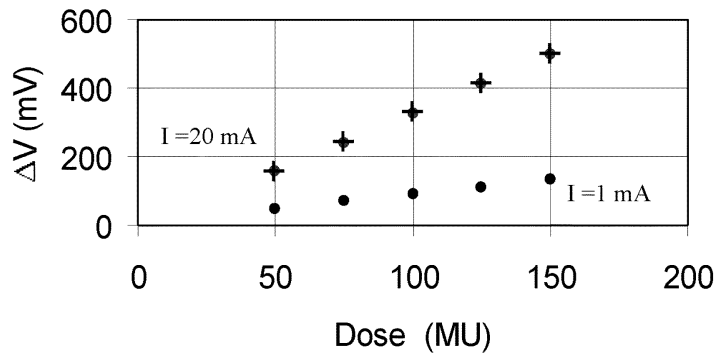

Fig. 10. Neutron response of the C-2 diode.

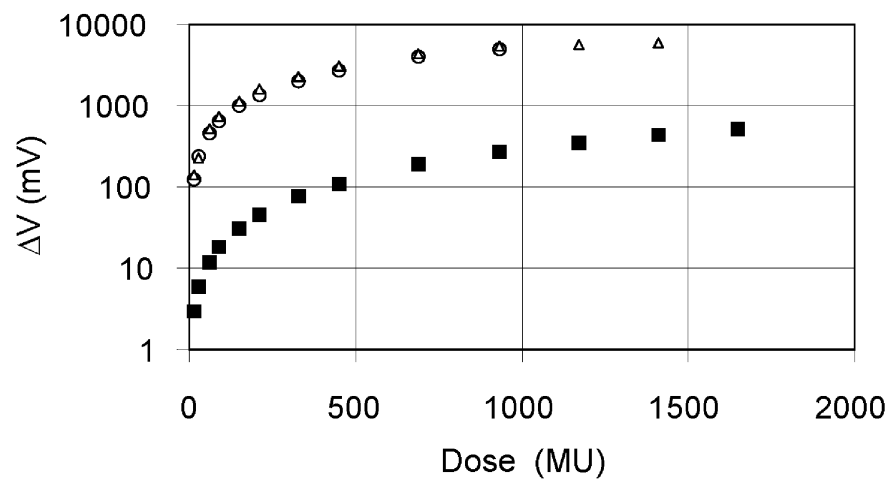

Fig. 11. Response of MD-1 p-i-n linear array diode for readout current $0.16 \mathrm{~mA}$ for first (circles) and second (triangles) and third (squares) diode.

p-i-n diode. The C-2 diode was employed in an "edge-on" mode of operation; i.e., spatial resolution is $0.35 \mathrm{~mm}$ which is impossible to achieve with IC.

Irradiation of all planar pin diodes was done in a water phantom using the neutron beam at the FNT facility. Diodes C1 and $\mathrm{C} 2$ were placed in a A-150 TE plastic jig ( $15 \mathrm{~mm}$ diameter and $13.5 \mathrm{~cm}$ in length) and were irradiated at a depth of $2.5 \mathrm{~cm}$ on the central axis of the $15 \times 15-\mathrm{cm}^{2}$ beam. Measurement of $\Delta V_{\mathrm{f}}$ was done immediately after irradiation. The L-type diodes were irradiated at a depth of $1 \mathrm{~cm}$ in an A-150 plastic phantom.

Figs. 9 and 10 show the neutron response of the C-1 and C-2 planar diodes for depth $5 \mathrm{~cm}$ in water for two readout currents 1 and $20 \mathrm{~mA}$. The sensitivities were 0.14 and $0.30 \mathrm{mV} / \mathrm{MU}$ for $\mathrm{C}-1$ diode and 0.88 and $3.32 \mathrm{mV} / \mathrm{MU}$ for $\mathrm{C}-2$ diode. (1 MU $1 \mathrm{cGy}$ at the point of irradiation).

Fig. 11 shows the response of $\mathrm{L}$ p-i-n linear array diode for readout current $0.16 \mathrm{~mA}$ for first and second and third $\mathrm{p}+$ pad. For each neutron dose, the voltage drop was measured between $\mathrm{n}+$ pad and consecutive $\mathrm{p}+$ pad. The dose increments were 15 MU. The sensitivities for first $\left(n^{+}-A\right)$, second $\left(n^{+}-B\right)$, third $\left(\mathrm{n}^{+}-\mathrm{C}\right)$, and fourth $\left(\mathrm{n}^{+}-\mathrm{D}\right)$ consecutive diodes were $0.2,8.4$, 
TABLE I

SENSitivity of Planar Diodes to Protons

\begin{tabular}{c|c|c|c|c}
\hline $\begin{array}{c}\text { Sensitivity } \\
\left(\mathrm{mV} / 10^{10} \text { protons } \mathrm{cm}^{-2}\right)\end{array}$ & A & B & C & D \\
\hline Device L & 18.6 & 1348 & 1462 & 1440 \\
\hline Device G & 71 & 1010 & 1289 & 1120 \\
\hline
\end{tabular}

9.4, and $8.6 \mathrm{mV} / \mathrm{cGy}$, respectively. All experiments were done at a depth of $1 \mathrm{~cm}$ in A-150 plastic phantom.

The circular and planar p-i-n diodes demonstrated high neutron sensitivity. Similar as in D-bulk diodes, the sensitivity is increasing with increasing planar base length and readout forward current. For C-type diodes, initial voltage drop and sensitivity depends on the radial base length as defined in Fig. 1. For a high injection current of $20 \mathrm{~mA}$, the ratio of sensitivities is about 11 for diode $\mathrm{C}-2$ and $\mathrm{C}-1$, which is proportional to $\mathrm{t}^{2}$, where $t$ is the radial base length, similar to the bulk diode [2].

For planar L-type p-i-n array diode, it is possible to achieve wide range of sensitivities. The small difference in sensitivities between second and third diodes is related to small injection current and geometry of $\mathrm{p}^{+}$pads. The lower sensitivity of the fourth consecutive diode is most likely related to the complicated geometry of the diode array.

\section{Proton Irradiation and Study of IEL Response of Neutron Irradiated Diodes}

The L and G-type planar p-i-n diodes were irradiated using $3-\mathrm{MeV}$ protons up to a fluence of $4.7 \times 10^{11} \mathrm{p} / \mathrm{cm}^{2}$. Table I shows the sensitivity for first (A), second (B), third (C), and fourth (D) consecutive diodes. Similar to the trend observed with neutron irradiation of the L-type diode array, the sensitivity of the fourth diode (D) is slightly less than the third diode (C).

To investigate the effect of any NIEL damage on IEL measurements with the same planar p-i-n diodes, we studied the charge collection in C-2 diode before and after irradiation with a neutron dose of $3 \times 10^{11} \mathrm{n} / \mathrm{cm}^{2}$ at the FNT facility. For this investigation, we used the IBIC technique described earlier. The C-type diodes displayed excellent current voltage characteristics after neutron irradiation. We were able to apply more than $500 \mathrm{~V}$ of reverse bias without breakdown occurring. The current at $500 \mathrm{~V}$ was $20 \mathrm{nA}$. Fig. 12 shows an optical image of one of the C-type diodes with the $2 \times 2-\mathrm{mm}^{2}$ IBIC scan area superimposed.

Fig. 13 shows an image of the median energy $E(x, y)$ for the IBIC scans. For $0-\mathrm{V}$, charge collection events are only registered for beam located close to the central $\mathrm{p}^{+}$region. At a reverse bias of $400 \mathrm{~V}$, the lateral depletion region extends approximately $0.5 \mathrm{~mm}$ from the $\mathrm{p}^{+}$region. The reverse current at this operating voltage was measured at $20 \mathrm{nA}$. There was no significant difference in the scan imaged between the nonirradiated and irradiated planar diodes.

Fig. 14 shows the spectrum of energy events obtained from the ADC of the data acquisition system for IBIC scans on device $\mathrm{C} 2$. The spectrum at $0-\mathrm{V}$ reverse bias is characterized by a peak situated at approximately $1500 \mathrm{keV}$ with a tail extending to low energies. This is due to the thin depletion region, resulting

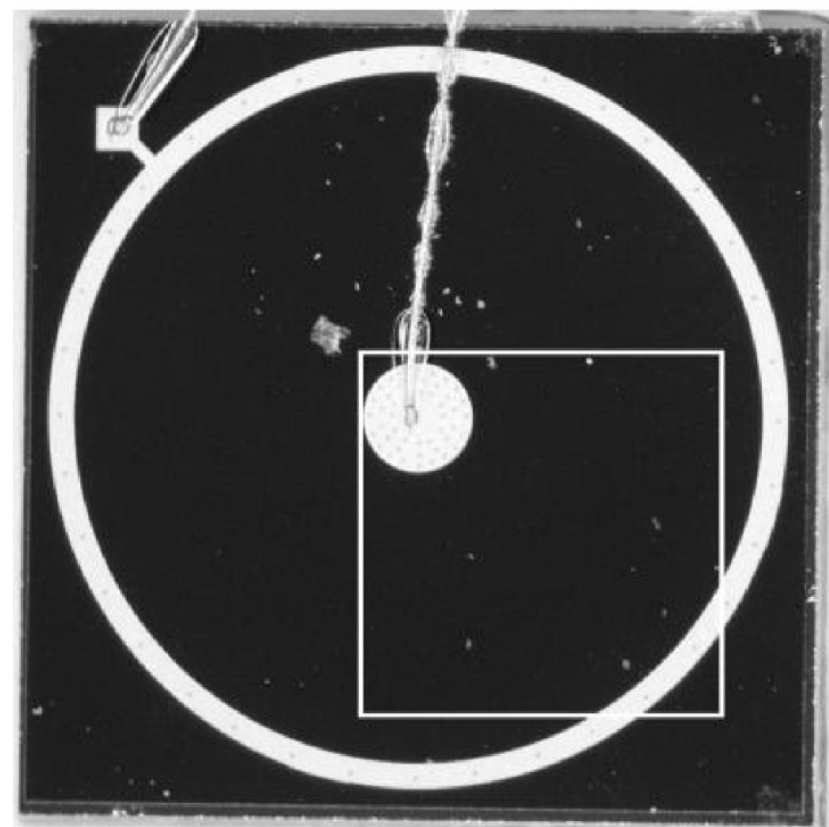

Fig. 12. The scan area is illustrated in the white square of Fig. 1. Optical image of $\mathrm{C} 2$ device, showing central $\mathrm{p}+$ region and outer $\mathrm{n}+$ ring. The scan area used in IBIC analysis is shown by the superimposed white square.

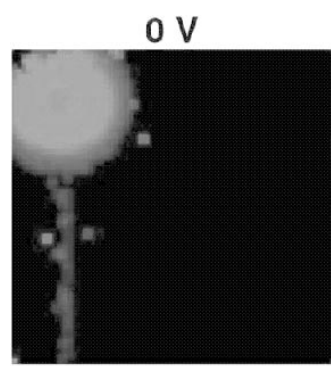

$0.1 \mathrm{MeV}$

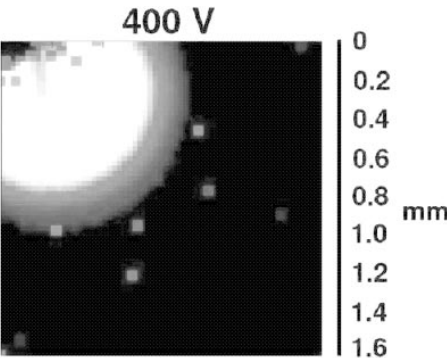

3. $0 \mathrm{MeV}$
Fig. 13. IBIC image of median energy event at each pixel of scan for device $\mathrm{C} 2$ at reverse bias of $0 \mathrm{~V}$ and $400 \mathrm{~V}$.

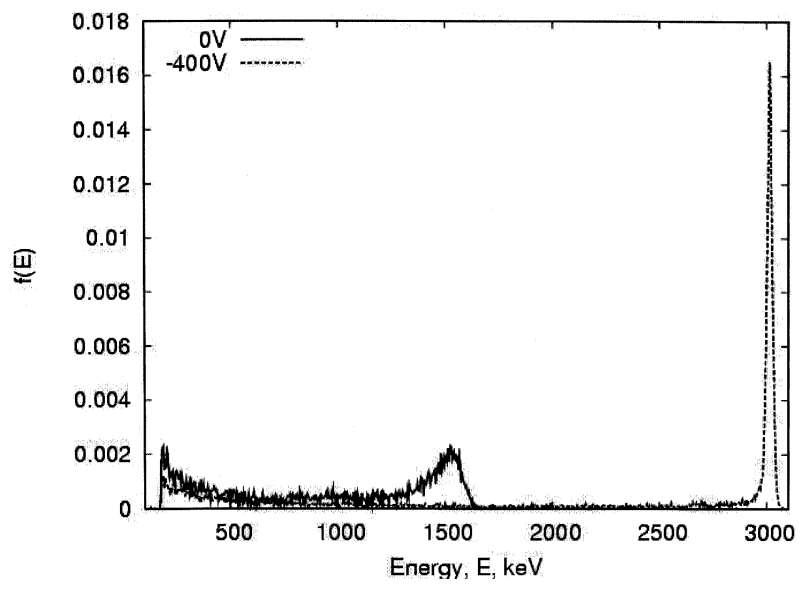

Fig. 14. Energy event spectra for IBIC scan of $\mathrm{C} 2$ device at reverse bias of $0 \mathrm{~V}$ (solid line) and $400 \mathrm{~V}$ (dashed line).

in charge collection being dominated by diffusion, and hence, events are subject to high recombination. The spectrum at $400 \mathrm{~V}$ is characterized by a sharp peak situated at $3000 \mathrm{keV}$, indicating 
complete charge collection and, hence, a depletion region thickness greater than the range of protons $(100 \mu \mathrm{m})$.

\section{DISCUSSION AND CONCLUSION}

The response of the bulk pin diode (D-type) and planar p-i-n diodes of different configurations (circular and linear array), based on high-resistivity silicon were investigated in fast neutron and $3-\mathrm{MeV}$ proton fields. Two aspects of the application of $\mathrm{p}-\mathrm{i}-\mathrm{n}$ diodes were investigated: possibility of TE neutron dosimetry for biological dose monitoring in space and application for NIEL and IEL monitoring with the same sensor. This application is important in high-energy physics for radiation damage monitoring systems in the silicon tracker.

For D-type diodes, a wide dose range was demonstrated. Both (C and D) have excellent ability to work on-line in the neutron field of FNT. These diodes can be used for neutron dose and dose rate measurements in on-line applications. On-line applications allow for the reduction in the error in the dose measurements associated with fading and temperature. Calibration should, however, be done in similar operating conditions as any on-line measurements. The changing neutron dose rate of 0.5 to $0.1 \mathrm{cGy} / \mathrm{s}$ showed a variation of response within $\pm 2 \%$ in the case of on-line measurements with D-diodes.

At any point in the medium, the response was shown to be associated with damage KERMA only, i.e., neutron fluence. The on-line application of planar diode in edge-on mode was shown to be useful for steep neutron dose-gradient measurements. The spatial resolution is limited by the thickness of the diode $(0.35 \mathrm{~mm})$. Planar $\mathrm{p}-\mathrm{i}-\mathrm{n}$ diodes, both circular in shape $(\mathrm{C} 1$ and $\mathrm{C} 2$ ) and a linear array, were investigated. It was demonstrated that C-type diodes are similar to D-type diodes that have $\sim \mathrm{t}^{2}$ sensitivity, where $\mathrm{t}$ is the radial distance between $\mathrm{p}+$ core and $n^{+}$periphery regions. The absolute sensitivity is also similar to D-type diodes with the same base length. L and G-type linear p-i-n diode array demonstrated similar response in neutron and proton $3-\mathrm{MeV}$ field. The relative response change between the A (first) to B (second) diode was 40-60 times, which makes them convenient for low-and high-neutron dose applications. The C-type diodes have a much more predictable response $\sim \mathrm{t}^{2}$, whereas $\mathrm{p}-\mathrm{i}-\mathrm{n}$ diode array do not appear to follow the $\mathrm{t}^{2}$ law. This variation from $\mathrm{t}^{2}$ is possibly due to a screening effect, i.e., strong nonuniformity in direction of readout current in L-and G-type p-i-n diode arrays in comparison with C-type diodes, which have radial symmetry. Further analysis is required for $\mathrm{L}$ and $\mathrm{G}$ sensor response characteristics.

Another advantage of C-type diode is in the strong electrical field near $\mathrm{p}^{+}$core region. Such diodes have essentially lateral depletion under reverse bias (about $0.5 \mathrm{~mm}$ for reverse bias $400 \mathrm{~V}$ ) and small reverse current. Even when damaged with neutrons $\left(\Phi_{\mathrm{n}} \sim 3 \times 10^{11} \mathrm{n} / \mathrm{cm}^{2}\right)$, the $\mathrm{C}-2$ diodes demonstrated
$100 \%$ charge collection from depletion area on a $3-\mathrm{MeV}$ proton beam.

Both diode types are more than suitable for use as IEL sensors, beam abort sensors in high-energy physics application or for space radiobiological applications for personal gamma-neutron dosimetry. For low-dose-rate gamma radiation, the sensor can be used in count mode for gamma dosimetry and forward voltage measurements for neutron dosimetry.

The best pin structure for neutron and gamma dosimetry, or NIEL and IEL, using the same sensor will be the C-type p-i-n structure with concentric $\mathrm{p}^{+}$regions to cover a wide neutron dose range to make possible full depletion and tolerance to NIEL in terms of constant sensitivity to IEL.

Further work will be done on investigation of multirange sensors with concentric $\mathrm{p}+$ regions that appear to be optimal for simultaneous NIEL and IEL measurements. Such structures, based on high-resistivity silicon, can be implemented on particle Si detectors working in harsh radiation environments.

\section{ACKNOWLEDGMENT}

The authors wish to thank the staff of SPO BIT/Detector for manufacturing of $\mathrm{p}-\mathrm{i}-\mathrm{n}$ structures and useful discussion. They also thank the staff of superconducting cyclotron and, in particular, J. Brandon of the FNT facility (Detroit) for support of experiments with electronic DAQ. Furthermore, they thank S. Mao (SLAC)_for support of measurements on the reactor.

\section{REFERENCES}

[1] A. J. Houdayer, P. F. Hinrichsen, A. L. Barry, and A. Ng, "GaAs LED based NIEL spectrometer for the space radiation environment," IEEE Trans. Nucl. Sci., vol. 47, pp. 533-538, 2000.

[2] J. M. Swartz and M. O. Thurston, "Analysis of the effect of fast-neutron bombardment on the current-voltage characteristics of a conductivity modulated p-i-n diode," J. Appl. Phys., vol. 37, no. 2, pp. 745-755, 1966.

[3] A. B. Rosenfeld, M. Reinhard, D. Marinaro, P. Ihnat, G. Taylor, L. Peak, N. Freeman, D. Alexiev, and M. Lerch, "System for radiation damage monitoring," IEEE Trans. Nucl Sci., vol. 46, pp. 1766-1773, Dec. 1999.

[4] A. B. Rosenfeld et al., "P-I-N diodes with a wide measurement range of fast neutron doses," Rad. Prot. Dos., vol. 33, no. 1/4, pp. 175-178, 1990.

[5] I. E. Anokhin, A. B. Rosenfeld, and O. S. Zinets, "Evolution of radiation induced defects and the type inversion in high receptivity silicon under neutron irradiation," Rad. Prot. Dos, vol. 101, no. 1/4, pp. 107-110, 2002.

[6] V. Starostova et al., "Properties of Chech Dosimetric Diode,"

[7] P. J. Griffin, J. G. Kelly, and D. W. Vehar, "Updated Neutron Spectrum Characterization of SNL Baseline Reactor Environments,", SAND932554, UC-713, Apr. 1994.

[8] T. D. Bohm, P. M. DeLuca Jr., R. L. Maughan, D. T. L. Jones, and A. Lennox, "Monte Carlo calculations to characterize the source for neutron therapy facilities," Med. Phys., vol. 26, pp. 783-792, 1999.

[9] R. Siegele, D. Cohen, and N. Dytlewski, "The ANSTO high energy heavy ion microprobe," Nucl. Instrum. Meth., vol. B158, pp. 31-38, 1999.

[10] I. Cornelius, A. Rosenfeld, R. Siegele, and D. Cohen, "IBIS characterization of silicon microdsimeters for space and medical application using a heavy ion microprobe," Nucl. Instrum. Meth. Phys. Res. B, vol. 19, pp. 335-338, 2001. 